Proc. Indian Acad. Sci. (Chem. Sci.), Vol. 89, Number 2, April 1980, pp. 139-144.

(C) Printed in India.

\title{
Surface tension measurements in the study of molecular complexes
}

\author{
RAM ADHAR SINGH, S P MISHRA and S N BHAT* India \\ Chemistry Department, Banaras Hindu University, Varanasi 221 005, India \\ * Chemistry Department, North-Eastern Hill University, Shillong 793 003,
}

MS received 4 June 1979 ; revised 27 August 1979

\begin{abstract}
Surface tension measurements can be used to investigate molecular complex formation in liquid solutions for strong and weak complexes. The association constant and epthalpy for triethylamine-iodine, hexamethylbenzene-tetracyanoethylene and ethanol-iodine in cyclohexane are $4.55 \times 10^{3}, 218$ and $0.93 \mathrm{M}^{-1}$ at $25^{\circ} \mathrm{C}$ and $12 \cdot 5,7 \cdot 7$ and $5 \cdot 1 \mathrm{kcal} / \mathrm{mol}$ respectively. These values compare well with those reported in the literature by other methods.
\end{abstract}

Keywords. Surface tension; molecular complexes.

\section{Introduction}

Ever since Benesi-Hildebrand (1949) reported the interaction of iodine with aromatics, a variety of physical methods, such as optical spectroscopy, magnetic resonance spectrossopy, calorimetry, etc. have been employed to investigate molecular complexes. However, it is surprising that even though, in principle, the formation of molecular complexes can be indicated and their composition established from a study of charasteristic abrupt departures from ideal behaviour in some physical properties, e.g., vapour pressure, sirface tension, refractive index, dielectric constant, etc., many of these methods are hardly used. The only information available using the surface tension measurement method is from Nayar et al (1952) who pointed out that a correlation may exist between surface tension minima and complex formation. Ferroni and Gabrielli (1956) also reported the feasibility of determination of the equilibrium constant for iodine-ethanol in carbontetrachloride. It was therefore felt worthwhile to study the interaction of electron donors and acceptors in solutions by using the surface tension measurement method and compare the results with those obtained by spectroscopic methods. We have chosen (i) the triethylamine-iodine system where the interaction between triethylamine and iodine is very strong, (ii) the hexamethylbenzene-tetracyanoethylene system where the interaction is medium, and (iii) the ethanol-iodine system, a typical case of weak interaction. 


\section{Materials and methods}

Cyclohexane, triethylamine, hexamethylbenzene, ethylalcohol and iodine were puriffed by using standard procedures. Tetracyanoethylene (DuPont) was recrystallised from chlorobenzene and purifted by vacuum sublimation.

The surface tensions of pure components and of different solutions of different compositions (at constant total molar concentration) at different temperatures $\left(25,30,35,40\right.$ and $\left.45^{\circ} \mathrm{C}\right)$ were measured in cyclohexane by the differential capillary rise method using a travelling microscope. The temperature of the solution was maintained constant $\left( \pm 0.1^{\circ} \mathrm{C}\right)$ by using a jacketed container through which water from a thermostat was circulated. The densities of the solutions at the same temperatures were measured by an Ostwald-Sprengel pyknometer. The experiments were repeated at least twice and the results were reproducible within the experimental error of $0.002 \mathrm{mN} / \mathrm{m}$.

\section{Results and discussion}

\subsection{Triethylamine iodine}

The surface tensions of triethylamine in cyclohexane and iodine in cyclohexane decrease with increase in concentration of the solutes. The surface tension of the solvent is very much changed by the addition of a very small amount of solute in the initial stage. Up to $1.0 \mathrm{mM}$, the surface tension is a non-linear function of concentration, but then becomes a linear function between 1 and $50 \mathrm{mM}$. The range of concentrations of triethylamine and iodine is such that when they are mixed, they form neutral complexes ; this was confirmed spectroscopically. The nonlinear plot of the surface tensions of the "mixed solution" against the concentration of triethylamine indicates the presence of a complex. For the sake of brevity, only one such set of data is given in table 1. A continuous variation plot of $\triangle \sigma$, the difference in surface tension between the "mixed solutions" and the calculated surface tensions of the two pure solutions, shows the presence of only $1: 1$ complex in the experimental range of concentration of 1 to $10 \mathrm{mM}$ of amine (figure 1); similar observations were made earlier by Bist and Person (1969) for triethylamineiodine by spectroscopy. As there is a linear relationship between $\Delta \sigma$ and the concentration of the complex, (i.e., similar to the test of Beer's law), we can conclude that if the two solutions show the same deviations of surface tensions, then they must have the same concentration of the complex (table 2) and the equilibrium constant for the system can be calculated by following the procedure adopted by Ferroni and Gabrielli (1956).

Consider the interaction of $\boldsymbol{A}$ with $D$,

$$
A+D \rightleftarrows A D \text {. }
$$

Let $C_{A}, C_{A}^{\prime}, C_{D}$ and $C_{D}^{\prime}$ be the initial concentrations of the acceptor and donor respectively for the two sets of solutions and $C_{A D}, C_{A D}^{\prime}$ be the concentration of the complexes. For the first set,

$$
K=C_{A D} /\left[\left(C_{D}-C_{A D}\right)\left(C_{A}-C_{A D}\right)\right]
$$


Table 1. Surface tensions of mixed solutions of triethylamine-iodine in cyclohexane at $25^{\circ} \mathrm{C}$.

\begin{tabular}{|c|c|c|c|c|}
\hline $\begin{array}{l}\text { Triethylamine } \\
\text { (millimoles) }\end{array}$ & $\begin{array}{c}\text { Iodine } \\
\text { (millimoles) }\end{array}$ & $\begin{array}{c}\text { Observed } \\
\text { surface } \\
\text { tension } \\
(\mathrm{mN} / \mathrm{m})\end{array}$ & $\begin{array}{l}\text { Calculated } \\
\text { surface } \\
\text { tension } \\
(\mathrm{mN} / \mathrm{m})\end{array}$ & $\underset{(\mathrm{mN} / \mathrm{m})}{\Delta \sigma}$ \\
\hline 0.5 & 9.5 & $23 \cdot 366$ & $23 \cdot 266$ & $0 \cdot 100$ \\
\hline $1 \cdot 0$ & $9 \cdot 0$ & $23 \cdot 376$ & $23 \cdot 260$ & $0 \cdot 116$ \\
\hline $1 \cdot 5$ & $8 \cdot 5$ & $23 \cdot 395$ & $23 \cdot 255$ & $0 \cdot 140$ \\
\hline $2 \cdot 0$ & 8.0 & $23 \cdot 401$ & $23 \cdot 250$ & $0 \cdot 151$ \\
\hline $2 \cdot 5$ & $7 \cdot 5$ & $23 \cdot 423$ & $23 \cdot 246$ & $0 \cdot 177$ \\
\hline 3.0 & $7 \cdot 0$ & $23 \cdot 430$ & $23 \cdot 234$ & 0.196 \\
\hline $3 \cdot 5$ & $6 \cdot 5$ & $23 \cdot 435$ & $23 \cdot 231$ & $0 \cdot 204$ \\
\hline $4 \cdot 0$ & $6 \cdot 0$ & $23 \cdot 448$ & $23 \cdot 221$ & 0.227 \\
\hline $4 \cdot 5$ & $5 \cdot 5$ & $23 \cdot 452$ & $23 \cdot 222$ & $0 \cdot 230$ \\
\hline $5 \cdot 0$ & $5 \cdot 0$ & $23 \cdot 458$ & $23 \cdot 220$ & 0.238 \\
\hline $5 \cdot 5$ & $4 \cdot 5$ & $23 \cdot 443$ & $23 \cdot 217$ & 0.226 \\
\hline 6.0 & $4 \cdot 0$ & $23 \cdot 365$ & $23 \cdot 212$ & $0 \cdot 153$ \\
\hline 6.5 & $3 \cdot 5$ & $23 \cdot 328$ & $23 \cdot 206$ & 0.122 \\
\hline $7 \cdot 0$ & $3 \cdot 0$ & $23 \cdot 277$ & $23 \cdot 205$ & 0.072 \\
\hline $7 \cdot 5$ & $2 \cdot 5$ & $23 \cdot 253$ & $23 \cdot 188$ & 0.065 \\
\hline $8 \cdot 0$ & $2 \cdot 0$ & $23 \cdot 239$ & $23 \cdot 185$ & 0.054 \\
\hline $8 \cdot 5$ & $1 \cdot 5$ & $23 \cdot 229$ & $23 \cdot 177$ & 0.052 \\
\hline 9.0 & $1 \cdot 0$ & $23 \cdot 209$ & $23 \cdot 173$ & 0.036 \\
\hline $9 \cdot 5$ & 0.5 & $23 \cdot 191$ & $23 \cdot 148$ & 0.043 \\
\hline
\end{tabular}

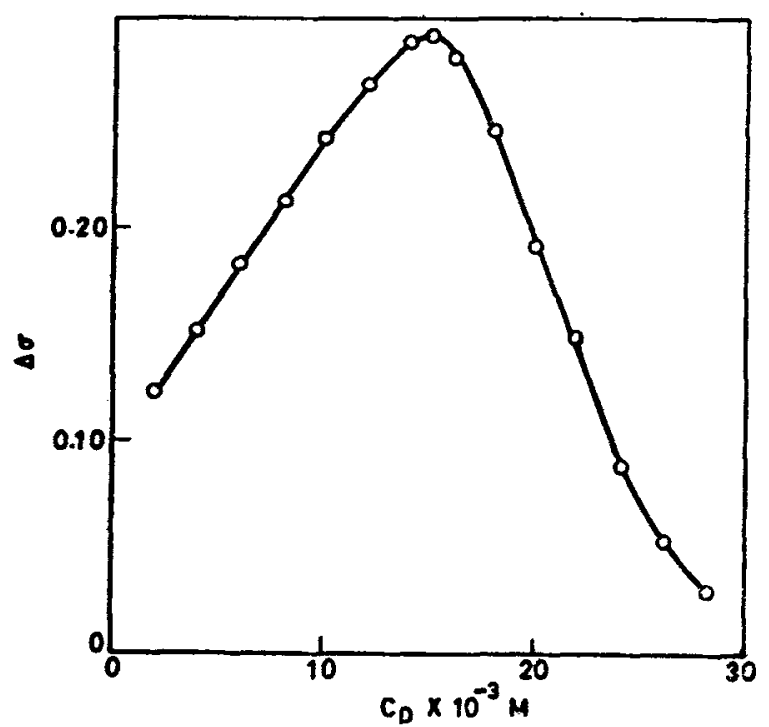

Figure 1. Plot of $\Delta^{\sigma}$ vs. donor concentration of triethylamine at $25^{\circ} \mathrm{C}$. 


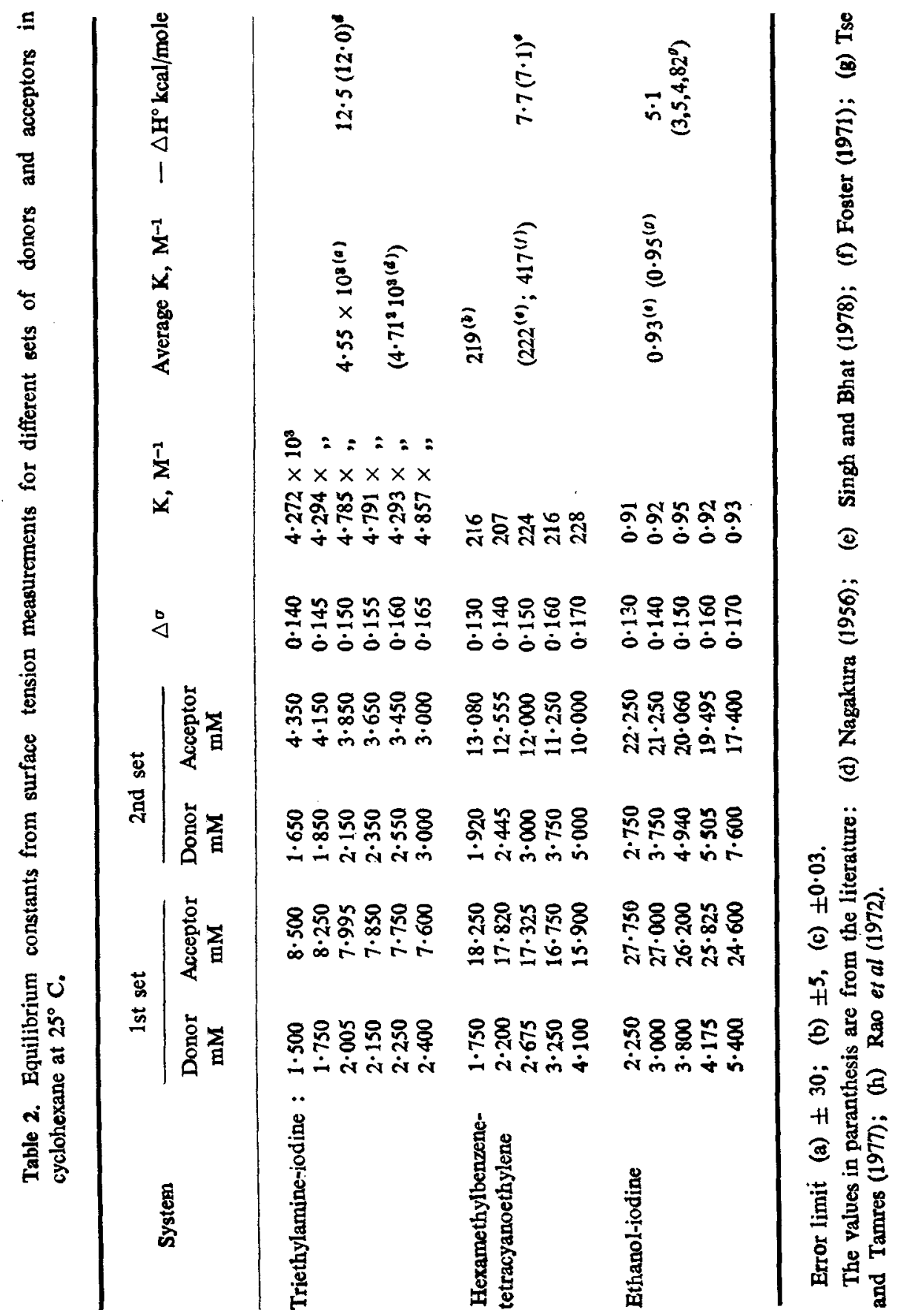


and for the second set,

$$
K=C_{A D}^{\prime} /\left[\left(C_{D}^{\prime}-C_{A D}^{\prime}\right)\left(C_{A}^{\prime}-C_{A D}^{\prime}\right)\right]
$$

Therefore

$$
C_{A D} /\left[\left(C_{D}-C_{A D}\right)\left(C_{A}-C_{A D}\right)\right]=C_{A D}^{\prime} /\left[\left(C_{D}^{\prime}-C_{A D}^{\prime}\right)\left(C_{A}^{\prime}-C_{A D}^{\prime}\right)\right] .
$$

If $\Delta \sigma_{1}=\Delta \sigma_{2}$, then $C_{A D}=C_{A D}^{\prime}$.

From the above equations, we get a $K$ value of

$$
\frac{\left(C_{A}^{\prime} C_{D}^{\prime}-C_{A} C_{D}\right)\left[\left(C_{A}^{\prime}+C_{D}^{\prime}\right)-\left(C_{A}+C_{D}\right)\right]}{\left[\left(C_{A^{2}}^{\prime}+C_{A} C_{D}\right)-C_{A}^{\prime}\left(C_{A}+C_{D}\right)\right]\left[\left(C_{D^{\prime}}^{\prime}+C_{A} C_{D}\right)-C_{D}^{\prime}\left(C_{A}+C_{D}\right)\right]^{\prime}}
$$

The $K$ values thus obtained for different sets of data at $25^{\circ} \mathrm{C}$ are given in table 2 , along with the enthalpies and it is clear that the equilibrium constants and enthalpies thus obtained are comparable to the values obtained by spectroscopic method by Rao et al (1972).

\subsection{Hexamethylbenzene-tetracyanoethylene}

The surface tensions of hexamethylbenzene and tetracyanoethylene in cyclohexane derrease with the insrease in concentration of solutes and there is a linear relation between the surface tension and the concentrations of solutes in the experimental range $\left(1 \times 10^{-8}-20 \times 10^{-3} \mathrm{M}\right)$ of concentrations. Higher concentrations of hexamethylbenzene and tetracyanoethylene are used as the interaction between these two is not that strong. The deviation from the ideal behaviour of the pure components is due to the interastion of the two species (donor and acceptor) and the deviation is proportional to the concentration of the complex. The plot of $\triangle \sigma$ against the concentration of hexamethylbenzene shows only one maximum at half the donor concentration indicating that hexamethylbenzene forms only $1: 1$ complex with tetracyanoethylene in the experimental range of concentrations. The termolezular complexes, may be formed only when the concentration of either of the components is very high.

The value of $K$ thus obtained for different sets of data are reported in table 2 along with the literature data. It is clear that the values of $K$ and $-\triangle H^{\circ}$ obtained by surface tension measurements are comparable to those obtained by Singh and B'hat (1978) by refractometry under similar conditions, but are quite low compared to the data reported by Foster and Kulevsky (1973). One of the possible reasons for this variation may be due to the different sets of experimental conditions. Tse and Tamres (1977) have also reported that the $K$ value depends on the experimental conditions such as whether $A \gg D, D \gg A$ or $A \approx D$ and also on the nature of solvent.

\subsection{Ethanol-iodine}

The surface tensions of ethanol in cyclohexane and iodine in cyclohexane decrease with in zrease in zon zentration of the solutes and there is a good linear relationship between the surface tension and concentration in the range $1 \times 10^{-3}-$ $30 \times 10^{-3} \mathrm{M}$. Higher concentrations of ethanol and iodine (total conc. $30 \times 10^{-8} \mathrm{M}$ ) 
are used as the interaction between ethanol and iodine is very weak. The small deviation from ideal behaviour of the pure components is due to the interaction of the two species (donor and asceptor) and the deviation is proportional to the concentration of the complex. The plot of $\triangle \sigma$ versus the concentration of ethanol shows only one maximum at half the donor concentration indicating that ethanol forms only $1: 1$ complex with iodine in the experimental range of concentrations.

The $K$ values calculated by the procedure described above are given in table 2 . The average value of $K$ is $0.931 \mathrm{~mole}^{-1}$ at $25^{\circ} \mathrm{C}$ and the enthalpy, $-\triangle H^{\circ}$ is $5.1 \mathrm{kcal} / \mathrm{mol}$. This value is comparable to the most recent reliable $K$ value $(0.95 \pm 0.06)$ reported by Tse and Tamres (1977). The higher value of $K$ reported by the earlier workers may be due to the interaction of ethanol with the solvent, namely $\mathrm{CCl}_{4}$ itself.

It therefore appears, that the method of surface tension measurements can be used not only to detext the formation of molecular complexes but also to determine the equilibrium constants and the thermodynamic properties of the complexes, even in the case of weak molecular complexes. However it may be interesting to examine closely related systems and then rationalise in terms of various effects.

\section{Acknowledgements}

The authors are thankful to Prof. M Tamres of University of Michigan, for providing capillary tubes, to Prof. O P Malhotra, Banaras Hindu University, to Prof. H Junjappa, Chemistry Department, for providing research facilities and to the University Grants Commission, New Delhi, for financial assistance.

\section{References}

Benesi H A and Hildebrand J H 1949 J. Am. Chem. Soc. 712703

Bist H D and Person W B 1969 J. Phys. Chem. 73482

Ferroni E and Gabrielli G 1957 J. Phys. Chem. 601258

Foster $\mathrm{R}$ and Kulevsky N 1973 J.C.S.F. Trans. I 691427

Nayar M R, Srivastava L N and Nayar K V 1952 J. Indian Chem. Soc. 29241

Rao C N R, Bhat S N and Dwivedi P C 1972 Appl. Spectrosc. Rev. 51

Singh R A and Bhat S N 1978 J. Phys. Chem. 822322

Tse H C and Tamres M 1977 J. Phys. Chem. 81 1367, 1376

Nagakura S $1957 \mathrm{~J}$. Am. Chem. Soc. 80520

Foster R 1971 J. Chem. Soc. (B) 1283 